\title{
Relationship between Computational Estimation and Problem Solving
}

\author{
Despina Desli ${ }^{{ }^{*}}$, Anastasia Lioliou ${ }^{1}$ \\ ${ }^{1}$ Aristotle University of Thessaloniki Faculty of Education, School of Primary Education, GREECE \\ *CORRESPONDENCE: $\square$ ddesli@eled.auth.gr
}

\begin{abstract}
The present study attempted to explore the relationship between computational estimation and problem solving in a sample of Year 6 children and adults $(\mathrm{N}=72)$. For this purpose, participants were presented with two tasks which asked them to estimate the computational result in eight arithmetic operations (Computational Estimation Task) as well as to provide solution to eight mathematical word problems, all coming from four different areas of mathematics (Problem Solving Task). The analysis of the results showed that adult participants accomplished more successful estimations compared to children, mostly with the use of rounding and algorithm strategies in both age groups. Age differences were also found in the Problem Solving Task with geometry and arithmetic problems being the most difficult for children and adults, respectively. Last, a significant positive correlation was revealed between estimation computational ability and problem solving ability: participants who had great success in computational estimation tended to indicate high success rates in problem solving. Educational implications are further discussed in terms of the role of computational estimation and problem solving in mathematics learning.
\end{abstract}

Keywords: computational estimation, problem solving, primary school mathematics

\section{INTRODUCTION}

A relevant part of the information we face every day demands our estimations the computation of which is often needed to make different decisions in almost all areas linked to everyday and professional life. Although estimation instruction has been overlooked in the past mathematics curriculum standards -mainly due to considerable interest given to fluent and precise written computations (Tsao, 2009), the study of computational estimation has been relatively recently included in the primary school curricula around the world (e.g., NCTM, 2000. DfE, 2013). With this incorporation these curricula recognize the importance of making reasonable computational estimations and suggest the enhancement of its instruction. The increasing emphasis placed on the field of computational estimation focuses on the idea that learning computational estimation could significantly help students' number sense and mathematical reasoning (McIntosh, 2005; McIntosh, Reys, \& Reys, 1992). Thus, mathematics is not viewed as a set of rules to be applied but as a way of thinking that allows people to handle and understand numbers as well as to make better mathematical judgments.

It is already known that there is a strong relationship between mental computation and mathematical reasoning (Kasmer, \& Kim, 2011. Gurbuz, \& Erdem, 2016). However, it is still important to determine whether there is such a relationship between computational estimation knowledge and a particular sector of mathematics education, that of problem solving. Although problem solving is apparently in the heart of mathematics instruction according to current curricular standards, many studies have proved that its

\footnotetext{
Article History: Received 19 May $2020 \bullet$ Revised 1 June $2020 \bullet$ Accepted 4 July 2020

(C) 2020 by the authors; licensee Modestum. Open Access terms of the Creative Commons Attribution 4.0 International License (http://creativecommons.org/licenses/by/4.0/) apply. The license permits unrestricted use, distribution, and reproduction in any medium, on the condition that users give exact credit to the original author(s) and the source, provide a link to the Creative Commons license, and indicate if they made any changes.
} 
cultivation can be effortful and error-prone (e.g., Doorman, Drijvers, Dekker, van den Heuvel-Panhuizen, de Lange, \& Wijers, 2007; Jitendra, \& Star, 2012; Silver, \& Cai, 1996).

\section{THEORETICAL CONTEXT AND LITERATURE REVIEW}

\section{Computational Estimation}

Computational estimation refers to determining an approximate but satisfactory solution to arithmetic computations with the use of mental mathematics. As it is one of the three types of estimation (with the others being numerosity estimation and measurement estimation) mentioned in the mathematics education literature (Hogan, \& Brezinski, 2003), it requires 'different kinds of understanding and different kinds of skills' (Sowder, 1992, p. 371). It is considered to be extremely important and, in some cases of ordinary everyday tasks, even more effective than precise computation: for example, to find out if the money are enough for a purchase or to compute the rough total amount to be paid, an estimated response may provide a contextually appropriate degree of precision.

Computational estimation offers an alternative way of developing concepts related to numbers (Reys, 1984). Thus, its beneficial effects on many mathematical abilities such as mental computation and number sense have given support of its role in mathematical cognition (Dowker, 2003; Sowder, 1992; van den HeuvelPanhuizen, 2001). More specifically, strong positive relationships have been found between estimation and better counting and arithmetic abilities (e.g., Booth \& Siegler, 2008; LeFevre, Greenham, \& Naheed, 1993) such as understanding of the place-value principle (Sowder, 1992). When a complex arithmetical task has to be computed or when a quick determination of a sum or a product is required, one can resort to computational estimation which is considered as a perceptual process that leads to an approximate judgment or calculation. This judgment is obviously less accurate than the precise calculation and demands a kind of translation between quantitative representations to take place: our ability to translate a complex arithmetical task into an estimated outcome reveals our focus on "the meaning of the numbers and the operations" (van de Walle, \& Lovin, 2006, p. 125). It seems that successful estimations require experience with numbers and counting which in turn allow estimators to approximate and verify answers to arithmetic tasks as well as to gain experience with large magnitudes that are beyond their current ability.

The vast majority of studies on computational estimation have been conducted with older children (upper primary school onwards) and adults with the use of both estimation production tasks and estimation comparison tasks (e.g., Ganor-Stern, 2015; Lemaire, \& Lecacheur, 2002). Participants are presented with an arithmetic problem and are asked to produce an estimate without calculating exactly in the first type, whereas in comparison tasks participants are given both an arithmetic problem and a reference number and they are asked to estimate whether the answer to that problem was larger or smaller than the reference number. Both types of tasks require conceptual and perceptual knowledge, since they require ways to simplify the arithmetic problem in order to solve it approximately as well as to apply these ways. The findings from these studies revealed that children and adults, apart from being quite poor estimators (Booth, \& Siegler, 2008), are affected by specific features of the arithmetic task (such as number size, arithmetic operation involved). Sekeris, Verschaffel, and Luwel (2019) provide a systematic review of the literature on computational estimation that describes its development as well as the age-related changes observed from kindergarten to the end of primary school.

In trying to interpret children's and adults' performance in computational estimation, considerable interest has been given to the role of their estimation strategies. These provide information about their general understanding of mathematical concepts, relationships and about their cognitive development in the domain of mathematics (Sowder, 1992). Three main strategies are often observed, mostly involving rounding procedures (Reys, Bestgen, Ryblot, \& Wyatt, 1982). The first which is known as 'reformulation' refers to changing numerical data to produce a more mentally manageable form. It may include 'rounding' (e.g., '48' is considered as ' 50 '), 'front-end strategy' (e.g., ' $342+426$ ' is considered as ' $300+400$ ') and 'truncating' (e.g., ' 423 +286 ' is considered as ' $420+280$ '). A second strategy found is that of 'translation', that is when the mathematical structure of the problem changes to a more mentally manageable form. For example, it may involve a change in the operation involved (e.g., ' $13+15+19$ ' is considered as ' $3 \times 15$ '). Whereas both reformulation and translation strategies refer to changes made for the numerical data to become more manageable, another strategy known as 'compensation' refers to adjusting an estimate to correct changes due to reformulation or translation (e.g., ' $94+78$ ' considered as ' $100+80=180$ ' and then is adjusted to ' 170 '). 
However, compensation strategy is mostly used by adults and quite rarely by young children (Reys et al., 1982).

As participants estimate first and then calculate, they may use their estimate as a sanity check in order to evaluate the reasonableness of their answers (Siegler, \& Booth, 2005; Yang, 2019). As they get older, they also refine their estimation strategies and improve their strategy selection processes (Lemaire, \& Lecacheur, 2011). When they freely explore computational estimation strategies before using formal written algorithms, they would use their number intuition, and sometimes would use non-regular methods to check the success of their estimates. McIntosh (2005) points out that exploring strategies for operating with numbers helps students develop their own strategies, far from using algorithms as a formula without understanding, and the connections with meaning are less likely to be lost. The urgency of cultivating computational estimation can also be found in the reasons for the use of computational estimation. Apart from the practical utility that computational estimation offers (Segovia, \& Castro, 2009), Usiskin (1986) refers to the 'ideals of mathematics', that is clarity in thinking and discourse, facility in dealing with problems, and consistency in the application of procedures' (Usiskin, 1986, p. 2). Thus, computational estimation is regarded as an important topic in mathematics education that needs to get considerable attention in order for its development to be encouraged early on.

\section{Mathematical Problem Solving}

Mathematical problem solving has long been seen as an important aspect of mathematics education, in particular of mathematics teaching and learning. As it is considered imperative that students are equipped with the skills needed to tackle problems, mathematics curricula around the world call for the teaching of problem solving as well as for the teaching of mathematics through (or via) problem solving (Schoenfeld, 1992; Stein, Boaler, \& Silver, 2003). However, problem solving poses many difficulties to younger and older students and does not seem to be a skill that is widely practiced and nurtured within classrooms (Lester, 2013).

In an effort to describe problems, most researchers agree that a problem is a task for which what needs to be done is not known and thus a potential solver does not know what to do to get an answer (e.g., Holth, 2008; Liljedahl, Santos-Trigo, Malaspina, \& Bruder, 2016). Problem solving refers, in addition to reaching the result, to the situation of finding a way, or relief from challenges (Polya, 1973). Conceptual understanding and procedural knowledge are essential to problem solving (Geary, 2004), as a variety of cognitive and noncognitive actions that require some knowledge and skills might necessitate a problem solver to get engaged. Given that problem solving is described as a characteristic of human activity (Polya, 1973) as well as all problems -including mathematical problems- may require no single solution to be applied, Polya identified four specific steps in solving mathematical problems, which consist of understanding the problem, devising a plan, carrying out the plan and looking back. Polya's theory and other theories that followed often serve as a guide for teachers and researchers to work with strategies performed by children and adults when dealing with solving mathematical problems.

Students' involvement in solving mathematical problems may be beneficial as it may improve and develop their ability to solve real-life problems, develop critical reasoning and understanding of the concepts, provide opportunities for the students to develop new solution strategies and modify knowledge they have already learned, among others (Schoenfeld, 1992. Lester, 2013). To accomplish effective contexts for problem solving processes to take place, principles and specifications of either 'good' mathematical problems (e.g., non-routine problems, open ended problems, rich problems) or 'good' problem solvers are often suggested (e.g., Cai, 2010; Liljedahl et al., 2016; Verschaffel, \& De Corte, 1997). Most of these suggestions focus on problem solving being taught as an integral part of mathematics learning, rather than as a separate topic in the mathematics curriculum. Thus, the effort to be made is to include problem solving at every grade level and with every mathematical topic.

Beyond mathematical problem solving, few studies have explored the relationship between mathematical reasoning and mental computation skills, and most of these studies have only employed simple measures of mathematical reasoning as wells as mathematical reasoning tasks that are given as a part of typical written school exams. For example, conceptual understanding of the equal sign has been found to be related to relational thinking and mental mathematics: when seventh-grade students were trained in mental mathematics, they were able to perform substitutions of equivalent expressions mentally and reasoned well (Kindrat, \& Osana, 2018). Similarly, fifth-grade students with a high level of mental computation were found by Gurbuz and Erdem (2016) to be successful in mathematics test and have a high level of mathematical reasoning. These relationships may reflect that mental computation development favors a stronger conceptual 
grasp of number properties and number sense (Sowder, 1992) which in turn supports mathematical reasoning. However, studies involving computational estimation -which is strongly connected to mental computation-, are required to confirm this. It is considered of great importance to further explore computational estimation as it may be useful in developing the potential of knowledge and skills in problem solving. The power of computational estimation and its importance to problem solving can also be seen in the strategies used when dealing with complex and cognitively demanding ideas in problems.

\section{The Present Study}

In an effort to replicate previous findings concerning the existence of a strong positive relationship between mental computation and mathematical reasoning, the present study moved beyond mental mathematics and looked at computational estimation using at the same time a measure of problem solving achievement that could be completed by both children and adults for purposes of direct comparison. Specifically, we addressed whether Year 6 children and adults differ in their ability to estimate and whether, as in studies on mental computation, individual differences in accuracy of estimates are related to problem solving. On these grounds, the main aim of the present study was to explore the relationship between computational estimation and problem solving, as drawn in the following research questions: a) How do Year 6 children and adults perform computational estimations? What is the reasoning they follow?, b) What is children's and adults' problem solving performance?, and c) Is there a relationship of both computational estimation performance and effective use of estimation strategies to problem solving success?

\section{METHOD}

\section{Participants}

A total of 72 participants (37 sixth-grade children and 35 adults) took part in the present cross-sectional study. Students (21 girls and 16 boys, aged from 11 years and 4 months to 12 years and 2 months, with mean age at 11 years and 8 months) were recruited from public primary schools of different cities of Greece in an effort to obtain greater geographical representativeness as well as variation in their socioeconomic and academic performance characteristics. Permission for students' participation was assured after written consent was given by their parents and teachers together with their own willingness to participate.

Of the 35 adult participants (ranging from 19 to 58 years of age, with mean age at 32 years) most (62\%) had university studies and 34\% completed high school. They were mostly women (55\%), employed (65\%) or students (19\%). Neither student nor adult participants had taken any typical instruction on computational estimation at school or outside school.

\section{Design and Measures}

Two tasks, one for computational estimation and one for problem solving, were designed and presented to all participants in one of two counterbalanced orders.

In Computational Estimation Task (CET - Appendix 1), participants were asked to perform computational estimations without using any means and without making accurate calculations. This task consisted of eight items which were formed on the basis of two different conditions: the type of arithmetic operation (addition, subtraction, multiplication, division) and the type of numbers (physical numbers, rational numbers). More specifically, in order to examine whether the computational success is affected by the type of arithmetic operation there were two items for each arithmetic operation. Similarly, in order to test whether the type of numbers (natural, rational) affects the computational ability, items with physical numbers and items with rational numbers were equally involved for each arithmetic operation. The physical numbers chosen were twodigit and three-digit numbers and the result of the operations with them did not exceed 3,500 (e.g., $476+338$ $=$ ?, $48 \times 76=$ ?). With regards to rational numbers, both decimal numbers and fractions were used (e.g., $0.8+$ $0.02=$ ?, 13/16 - 2/6 = ?). Consequently, the CET comprised four items requiring physical number computational estimations (one for each arithmetic operation) and four items that were concerned with rational number computational estimations (one for each arithmetic operation), which equally included decimals and fractions. The total number of successful estimations (see way of considering successful estimations in the 'Data Coding' section) was used as an indicator of participants' computational estimation ability. The Cronbach's alpha coefficient of internal consistency for this task was .91. 
The Problem Solving Task (PST - Appendix 2) consisted of a total of eight items and required participants to solve word mathematical problems, all coming from four specific mathematical areas: arithmetical operations, geometry, probability and patterns. Specifically, there were two items for each area and they were all referred to everyday life situations. These problems demand consideration of the reality of the situation described and many of them cannot be solved by using straightforward arithmetic operations. This task was based and extended the research tool used by Gurbuz and Erdem (2016) in their mathematical reasoning test: either verbal or numerical modifications were done (e.g., items A and C) to the original version of the tool in order to make the problems more appropriate for younger children, whereas other items remained unchanged (e.g., item D) or were redesigned (e.g., items E and F). The total number of correct responses were used as an indicator of performance on mathematical word problem solving. The Cronbach's alpha reliability values for this task were .83 .

Children and adults were randomly assigned to two groups (Groups A and B) according to the way the tasks were presented to them. Participants from Group A were presented with the Computational Estimation Task as consisting of open-ended items and were asked to provide a response which came from their own estimation. They were, however, presented with the Problem Solving Task as consisting of multiple choice items in which they had to choose their response among three responses given to them. The exact opposite way of presentation among the tasks was followed for participants in Group B. The multiple choice responses in both Tasks were designed so that, depending on the distance between estimation and accurate result or depending on the mathematical area underlying each problem for CET and PST respectively, only one response could be considered as accurate and therefore correct.

\section{Procedure}

Participants were interviewed individually in a quiet area and their responses were voice-recorded. Children were assured that their scores in the tasks would not count in terms of their mathematics course grade. Prior to presenting the tasks, all participants were provided with the opportunity to familiarize themselves with the experimenter. The instructions and the presentation of the tasks were given orally. No feedback or clarification was provided to any participant at any time during the tasks delivery. Participation in the study was completely voluntary and anonymous. The procedure lasted roughly 20-25 minutes.

\section{Data Coding}

Following the criteria used in studies examining adults' and children's estimation rates (e.g., Dowker, 1992, 1997), successful estimates are considered the reasonable estimates which in turn are defined as those that are within $20 \%$ or $30 \%$ of the correct answer. In the Computational Estimation Task of the present study, successful responses were considered any responses that were less than $20 \%$ of the exact result $(+/-20 \%)$, or else, their estimation error did not exceed $20 \%$ of the exact answer. For example, in the addition of $0.8+0.02$ -in which the exact result is 0.82 - the responses ranging from 0.656 to 1 were considered correct.

For the statistical analysis presented in this paper, 1 point was attributed if a participant gave a correct response, whereas unsuccessful responses were assigned 0 points. The points were summed to obtain a total score, which could reach a possible of 16 points. The data were analyzed using statistical package for the social sciences (SPSS 25).

\section{RESULTS}

\section{Rates of Correct Responses}

Descriptive statistics for participants' performance on each of the tasks are provided in Table 1, which demonstrate that there was good variance in performance on each task, without evidence of floor or ceiling effects. Below we first explore performance on each task in more detail before going on to explore the relationship between computational estimation and problem solving. 
Table 1. Descriptive statistics for CET and PST tasks

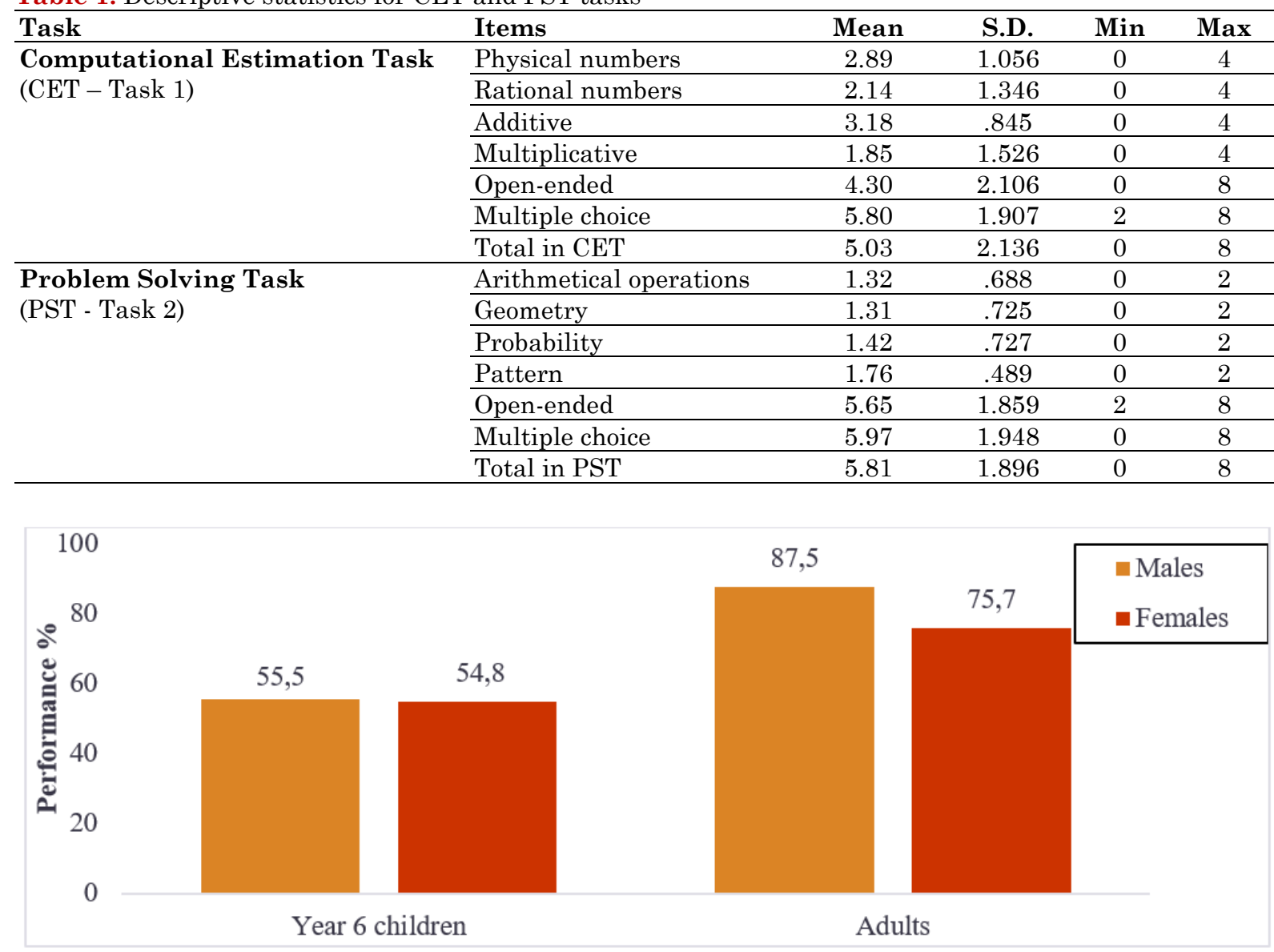

Figure 1. Percentage of total correct responses by age and gender

Participants' performance in the total of items coming from both tasks exceeded $68 \%$. However, as depicted in Figure 1, significant differences were observed between the two age groups $(t=-5.726, d f=70, p<.001)$, with success rates close to $55 \%$ for sixth graders and $81 \%$ for adults. No statistical significant gender differences were found in participants' performance $(t=1.241, d f=70, p=.219)$ with males and females offering similar percentages of successful estimates. This finding was also revealed when the analysis was carried out separately for each age group $(t=.118, d f=35, p=.907$ and $t=1,740, d f=33, p=.091$, for Year 6 children and adults, respectively). Task presentation affected participants' performance $(t=-2.140, d f=70, p=<.05)$, with participants in Group B showing significant better performance (73.5\%) compared to participants in Group A $(62.2 \%)$.

\section{Performance in computational estimation task}

A three-way mixed model ANOVA was conducted in order to analyse the effects of age (Year 6 and adults) and gender (males and females) as the between-subjects factor, and type of numbers (physical and rational numbers) as the within subjects factor. The main term of the type of numbers was significant $(F(1.68)=4.672$, $p<.001)$, with all the participants having better rates of correct responses when estimating with physical rather than with rational numbers. There was a significant main effect of age $(F(1.68)=-5.029, p<.001)$, indicating that the adults performed significantly better than the sixth graders. No significant gender effect was found $(F(1.68)=1.638, p=.118)$. Neither the interaction between age and type of numbers $(\mathrm{F}(1.68)=3.012$, $\mathrm{p}=.676)$ nor the one between gender and type of numbers $(F(1.68)=.260, p=.418)$ nor the interaction between age, gender and type of numbers was significant $(F(1.68)=2.294, p=.153)$, showing that differences in participants' performance among items with physical numbers and items with rational numbers was not affected by age and gender. That means that both age groups and both gender groups performed significantly better when computing estimations with physical numbers rather than with rational numbers. Figure 2 shows the interaction between age and type of numbers. 


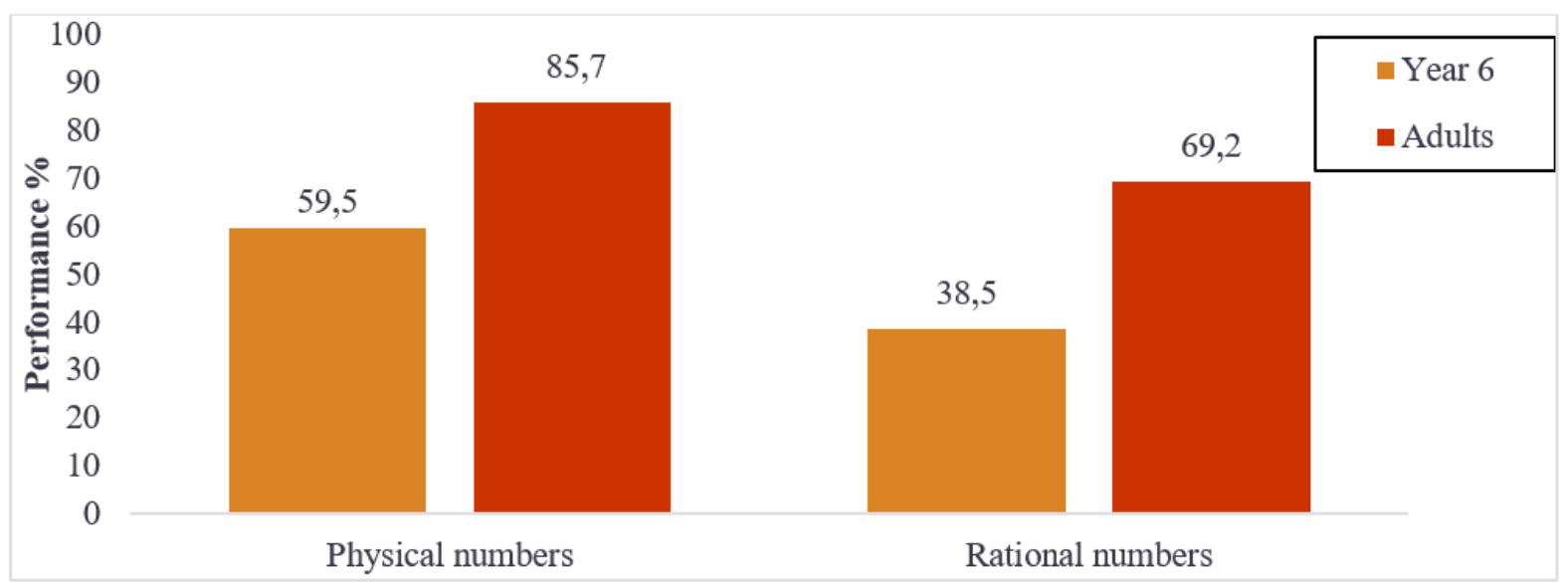

Figure 2. Percentage of correct responses by type of number and age in Computational Estimation Task

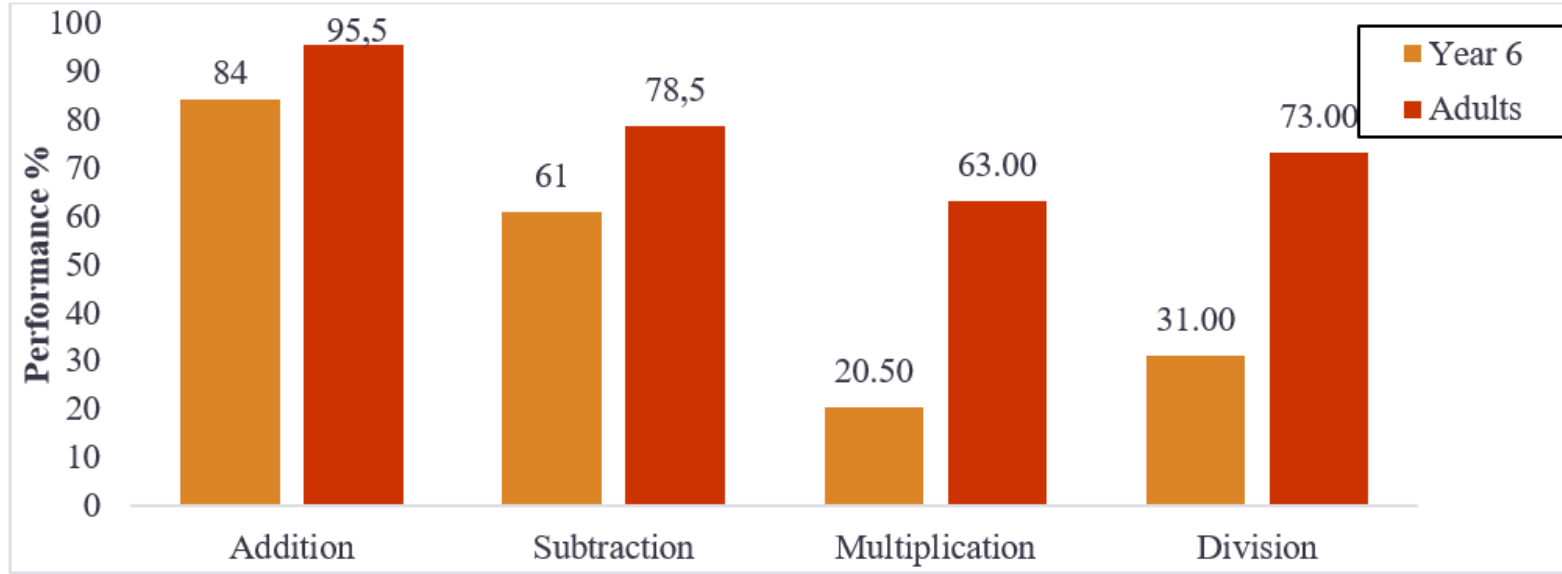

Figure 3. Percentage of correct responses by type of arithmetic operation and age in Computational Estimation Task

The values of the t-test paired, that was carried out in order to examine whether the type of arithmetic operation had an effect on estimation performance, revealed that both Year 6 children and adults managed to obtain statistically better scores in the addition and subtraction items (79.5\%) rather than in the multiplication and division items (46.2\%) $(t=10.223, d f=36, p<.001$ and $t=4.098, d f=34, p<.001$ for Year 6 children and adults, respectively). When further analyses were carried out for each arithmetic operation and for each age group separately, it was found that there were significant differences in the performance of participants between addition and subtraction items $(t=4.617, d f=36, p<.001$ and $t=3.762, d f=34, p<.01$ for Year 6 children and adults, respectively). However, no significant differences were found in the performance of participants between multiplication and division items $(t=-1.484, d f=36, p=.146$ and $t=-1.747, d f=34, p=.090$ for Year 6 children and adults, respectively). These results are illustrated in Figure 3.

\section{Analysis of participants' justifications in CET}

Further to their responses to estimates, participants were asked to justify their answers in CET, independently of whether they were correct or not. These justifications revealed the strategies they employed and were classified on the basis of what reasoning they used in order to perform computational estimations, giving five distinct and ordered categories which are explained below.

0. Idiosyncratic responses. Participants who gave responses that do not indicate any justified strategy (such as 'it seems so', 'I made it in my mind') and/or were not able to justify their estimates ('I don't' know') were included in this type of justification.

1. Rounding. This type of justification was given by participants who first rounded the numbers up or down to the nearest decimal place and then performed the estimation mentally with the new -easily calculated- numbers. In other words, they tried to make initial numbers simpler but kept their values 


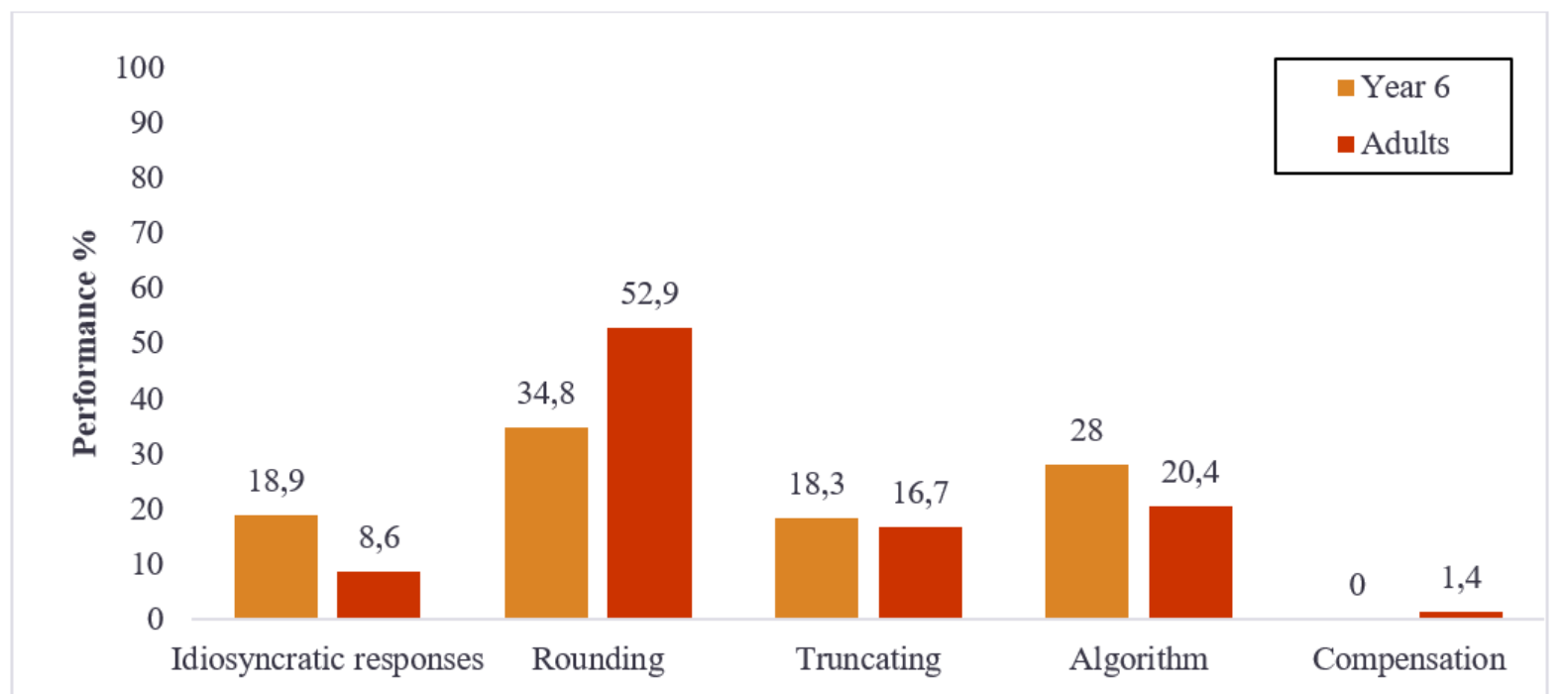

Figure 4. Percentage of responses in each type of strategy by age in Computational Estimation Task

close to what they were (e.g., for the sum $476+338$, they said ' $500+300=800$, so it is about 800 '; for the product $48 \mathrm{X} 76$, they said ' $50 \mathrm{X} 80=4000$, so it is about 4000').

2. Truncating. Participants who used this type of strategy based their responses on the relative size of the numbers as well as the place value of the front digit. Thus, they kept the first and/or the second digit in each of the numbers and changed all the other digits to zeros (e.g., they converted the sum $476+338$ to' $470+330=800^{\prime}$ and said 'it is about $800^{\prime}$ ').

3. Algorithm. This type of justification was shown by participants who applied an algorithm for the computational estimate asked by mentally following the step-by-step procedures that are normally associated with an arithmetic operation and reached an exact solution. In other words, they mentally computed the algorithm of an operation as if it was with paper and pencil.

4. Compensation. This type of justification indicates participants' ability to first make a computational estimate and later adjust it to make it closer to the exact answer (e.g., for the product 48X76, they said ' $40 X 70=2800$, but 48 is more than 40 and 76 is more than 70, so the estimated answer is a little more than 2800, it is about 3000'). This type of strategy, often also known as 'adjusting strategy' (Reys, 1984), was often observed after rounding or truncating strategy was used.

Although the majority of the participants seemed to use rounding and algorithm strategies, significant differences between age groups were found, with regards to the types of strategies used. More specifically, almost one in two adults (52.9\%) and one in three students (34.8\%) used the rounding strategy, with statistically significant differences in its use among the two age groups $(t=-3.201, d f=70, p<.01)$. However, both age groups used the truncating strategy (frequency use around 18\%) as well as the algorithm (frequency use around 25\%) with similar frequency $(t=.438, d f=70, p=.662$ and $t=1.474, d f=70, p=.145$ for truncating strategy and algorithm, respectively). Estimates based on idiosyncratic responses were significantly more often used by the Year 6 children than by the adults $(t=2.816, d f=70, p<.01)$. Figure 4 sets out the percentage of responses per age group involving the different types of strategies for computational estimation items.

\section{Performance in problem solving task}

The rate of success in PST exceeded 70\%, with great deviations between Year 6 children (61.1\%) and adults $(84.6 \%)$.

The mean number of correct responses was subjected to a mixed Analysis of Variance in which age (2: Year 6 children and adults) and gender (2: males and females) were the between-subjects factors and type of mathematical area (4: arithmetical operations, geometry, probability and patterns) was the within subjects factor. The main term of type of mathematical area was significant $(F(1.68)=6.341, p<.01)$, indicating that the participants performed significantly better in the pattern items (about 88\%) than in the arithmetical operations, geometry and probability items (about 66\%, 65\% and 70\%, respectively). More specifically, performance in the pattern problems was significantly better than in the arithmetical operations problems 

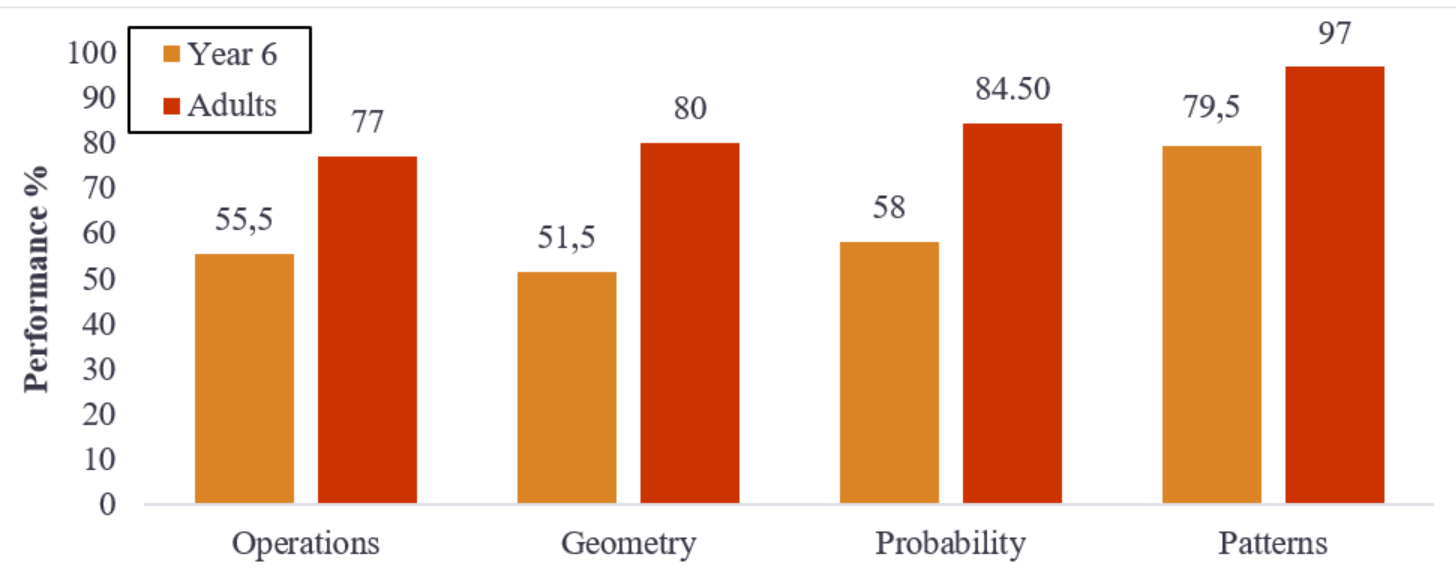

Figure 5. Percentage of correct responses by age and types of mathematical areas in Problem Solving Task

Table 2. Pearson's correlations between CET and PST by age

\begin{tabular}{llccc}
\hline & & $\begin{array}{c}\text { Overall } \\
\text { achievement }\end{array}$ & CET & PST \\
\hline Computational Estimation & Year 6 children & $.802^{* *}$ & - & $.420^{* *}$ \\
\cline { 2 - 5 } Task & Adults & $.969^{* *}$ & - & $.802^{* *}$ \\
\cline { 2 - 5 } $\begin{array}{l}\text { PeET - Task 1) } \\
\text { Problem Solving Task }- \text { Task 2) }\end{array}$ & Total & $.929^{* *}$ & - & $.690^{* *}$ \\
\cline { 2 - 5 } & Year 6 children & $.880^{* *}$ & - & - \\
\cline { 2 - 5 } & Adults & $.925^{* *}$ & - & - \\
\hline
\end{tabular}

$* * p<.01$

$(t=-5.313, d f=71, p<.001)$, in the geometry problems $(t=-5.471, d f=71, p<.001)$ and in the probability problems $(t=-4.119, d f=71, p<.001)$.

The interaction type of mathematical area by age was not significant $(F(1.68)=4.902, p=.523)$. Further analyses showed that both Year 6 children and adults outperformed in pattern problems $(79.5 \%$ and $97 \%$, respectively) compared to their rates of success in operations, geometry and probability problems $(t=-3.683$, $d f=36, p<.01, t=-4.312, d f=36, p<.001$ and $t=-3.151, d f=36, p<.01$, for Year 6 children, respectively $/ \mathrm{t}=-3.919$, $d f=34, p<.001, t=-3.431, d f=34, p<.01$ and $t=-2.704, d f=34, p<.05$, for adults, respectively). Participants' performance in the four types of mathematical areas by age is presented in Figure 5. The two way interaction type of mathematical area by gender was not significant $(F(1.68)=1.806, p=.784)$. The three way interaction type of mathematical area by age by gender was also not significant $(F(1.68)=.647, p=.477)$.

\section{Computational Estimation and Problem Solving}

Pearson's correlations were computed between each measure which showed, as seen in Table 2, that computational estimation scores were strongly related to problem solving scores $(r=.690, p<.01)$, and this association remained significant after controlling for age group $(r=.420, p<.01$ and $r=.802, p<.01$ for Year 6 children and adults, respectively). It seems that participants -from both age groups- with a high level of computational estimation also reveal a high level of problem solving.

Participants' computational estimation scores as well as problem solving scores were also correlated with overall achievement $(r=.929, p<.01$ and $r=.909, p<.01$, respectively), meaning that participants who scored highly in each measure tended to obtain high total rates of success. These positive correlations were also confirmed with regards both to children $(r=.802, p<.01$ and $r=.880, p<.01$, respectively for CET and PST) and adults $(r=.969, p<.01$ and $r=.925, p<.01$, respectively for CET and PST).

Finally, Pearson's correlations were used in order to examine if there is a relationship between participants' performance and their reasoning as indicated in the types of justifications they used in CET. As shown in Table 3, the use of rounding strategy was significantly positively correlated with total success rates as well as with success rates in CET and PST, for both Year 6 children $(r=.590, p<.01, r=.568, p<.01$ and $r=.443$, $p<.01$, respectively) and adults $(r=.520, p<.01, r=.569, p<.01$ and $r=.381, p<.01$, respectively). On the contrary, idiosyncratic responses were significantly negatively correlated with success in all measures for both age 
Table 3. Pearson's correlations between strategy use in CET and performance by age

\begin{tabular}{llccc}
\hline Strategies & & Overall achievement & CET & PST \\
\hline Idiosyncratic responses & Year 6 children & $-.706^{* *}$ & $-.591^{* *}$ & $-.601^{* *}$ \\
\cline { 2 - 5 } & Adults & $-.507^{* *}$ & $-.514^{* *}$ & $-.433^{* *}$ \\
\hline \multirow{2}{*}{ Rounding } & Year 6 children & $.590^{* *}$ & $.568^{* *}$ & $.443^{* *}$ \\
\cline { 2 - 5 } & Adults & $.520^{* *}$ & $.569^{* *}$ & $.381^{* *}$ \\
\hline Truncating & Year 6 children & -.109 & -.223 & -.111 \\
\cline { 2 - 5 } & Adults & .003 & .022 & -.026 \\
\hline Compensation & Year 6 children & .045 & -.003 & .071 \\
\cline { 2 - 5 } & Adults & $-.337^{*}$ & $-.395^{*}$ & -.208 \\
\hline
\end{tabular}

$* * p<.01$

${ }^{*} p<.05$

groups. It seems that when children and adults used the rounding strategy they tended to give correct responses, whereas the more often they gave idiosyncratic responses the less successful they were.

No correlations were found at all between both truncating and compensation strategies use and performance, meaning that these types of strategies were observed both with successful and not successful responses. However, adults' use of algorithm in CET was negatively associated with their CET performance $(r=-.395, p<.05)$ as well as with their overall correct score $(r=-.337, p<.05)$. Interestingly, adults who based their estimations on algorithm computation tended to provide unsuccessful estimations, whereas not such a trend was revealed with regards to Year 6 children.

\section{DISCUSSION}

The present study tried to explore the relationship between computational estimation and problem solving in a sample of Year 6 children and adults. Since the existence of a strong relationship between mental computation and mathematical reasoning is already known from existing research, it was in our interest to determine whether there is such a relationship between computational estimation knowledge and problem solving, recognizing the importance of problem solving as part of mathematics curriculum and looking at the accuracy and strategy use of $6^{\text {th }}$ graders and adults. Two main issues were revealed.

First, children's as well as adults' successful computational estimation performance was highly correlated with mathematical problem solving achievement. In other words, participants with a high level of computational estimation were found to have a high level of problem solving. The finding concerning the strong relation between computational estimation and problem solving was confirmation of previous studies which concluded that the solution of a mathematics problem requires not only some adjustment of the numbers but also a reflection on what adjustments are made before coming up with a reasonable estimate (McIntosh et al., 1992; McIntosh, 2005). On these grounds, Kasmer and Kim (2011), Gurbuz and Erdem (2016) and Kindrat and Osana (2018) consequently identified that mental computation and mathematical reasoning are intertwined and should be considered together as the prominent role of mental mathematics in the mathematics classroom is recognized. The fact that the present study revealed an evidence for the relationship between computational estimation and problem solving may also depict a developmental pattern between children and adults, given that there was an increase in accuracy with age in both parts of the relationship. This increase was quite constant with regards to participants' better performance on estimations with whole numbers compared to rational numbers and on addition and subtraction estimations compared to multiplication and division estimations. Interestingly, this increase was limited to problem solving trials that involved pattern in which both age groups outperformed; however, the adult group performed equally better in operations, geometry and probability problems than the students group. These findings are consistent with cognitive development theories in that problem solving abilities differ among individuals and they subsequently become more complex and sophisticated at each advanced stage. Thus, the application of cognitive development theories to instruction might be necessary (Frederiksen, 1984). It is possible that computational estimation would fit well with these theories and the relationship between problem solving and computational estimation might be better established with the development of instructional strategies that move solvers to higher cognitive developmental stages representative of more complex problem solving demands. 
Second, although rounding strategy was the dominant strategy in computational estimation items and its use differed among age groups, it was strongly related to both successful estimations and successful solutions in mathematics problems. More than half of the adult participants and more than a third of the student participants preferred to use the rounding strategy and were more likely to produce a correct response regarding their estimations as well as their problem solutions. Adults exhibited more variability in strategy use compared to children, as using a range of strategies was much more common among adults than among children. This pattern of using a wider range of strategies across older age groups has been reported in the literature (Lemaire, \& Lecacheur, 2002, 2011). The analysis of participants' justifications further reveals that children and adults with success in problem solving appear to engage in meaningful estimations with the use of effective strategies, confirming again the link between computational estimation and problem solving.

A quite large number of participants though did use mental image of the standardized algorithm (28\% and $20.4 \%$ for children and adults, respectively), without necessarily reaching success either with their computational estimates or with their solutions. The great emphasis on the mentally applying algorithms observed in both age groups has important implications, particularly with respect to computational estimation, as researchers have previously argued that individuals who struggle to provide estimations appear to engage in meaningless precise computations with the use of the algorithm instead of reflecting on the relationships between numbers (Ganor-Stern, 2015; Reys et al., 1982; Sekeris et al., 2019; Sowder, 1992). It seems that an algorithmic calculation is not an indication of conceptual understanding and, therefore, the application of the algorithm does not always lead to successful answers. One explanation of this emphasis can be drawn from adult participants with lower levels of computational estimation who are found to show more evidence of using the strategy associated with the use of algorithms than adults with higher levels of computational estimation. Alternatively, children with bad computational estimation may make use of the algorithm but are also less able to extend this strategy to alternative computational estimation strategies, as for example, by identifying that 476 can be handled as 500 . With regards to children, in particular, the use of the algorithm strategy when dealing with tasks that required their estimates possibly restricted their use of other strategies, revealing their low flexibility in using alternative strategies.

Although primary school teachers often acknowledge computational estimation and its integration to the mathematics curriculum indicating its use in making decisions mathematically, they face difficulties to relate computational estimation to a task (Anestakis, \& Desli, 2014; Tsao, 2009). Given that previous findings on teachers' computational estimation attitudes reveal their intention to associate computational estimation with children's everyday experiences and activities as well as cultural practices, the need to provide students with the means to make the links between mathematical reasoning and problem solving seems to be more than imperative.

The study presented in this paper was a small scale study and, as such, care should be taken in interpreting the results. The findings are, however, in line with other research findings such as the existence of a relationship between mental mathematics and mathematical reasoning (Kasmer, \& Kim, 2011; Kindrat, \& Osana, 2018) as well as children's resilience to algorithms (McIntosh, 2005). Although the use of algorithm was not considered as efficient as the rounding strategy and did not lead to success in problem solving tasks, more critical approaches to computational estimation and their relation to mathematical reasoning need to be documented. Prior to solving problems, tasks in which children judge the expected answer and check the reasonableness of their responses might be helpful (Yang, 2019). In fact, making children more familiar with computational estimation skills and strategies quite early and allowing for mathematical judgments may have better effect on their success as problem solvers.

\section{Disclosure statement}

No potential conflict of interest was reported by the authors.

\section{Notes on contributors}

Despina Desli - Aristotle University of Thessaloniki Faculty of Education, School of Primary Education, Greece.

Anastasia Lioliou - Aristotle University of Thessaloniki Faculty of Education, School of Primary Education, Greece. 


\section{REFERENCES}

Anestakis, P., \& Desli, P. (2014). Computational estimation in the Greek primary school: Tasks proposed for its teaching. MENON: Journal of Educational Research, $1^{\text {st }}$ Thematic Issue, 75-89.

Booth, J. L., \& Siegler, R. S. (2008). Numerical magnitude representations influence arithmetic learning. Child Development, 79(4), 1016-1031. https://doi.org/10.1111/j.1467-8624.2008.01173.x

Cai, J. (2010). Helping elementary school students become successful mathematical problem solvers. In D.V. Lambdin, \& F.K. Lester (Eds.), Teaching and learning mathematics: Translating research for elementary school teachers (pp. 9-14). Reston, VA: NCTM.

Department for Education (2013). The National curriculum in England: Key stages 1 and 2 framework document. Retrieved from https://www.gov.uk/government/collections/national-curriculum

Doorman, M., Drijvers, P., Dekker, T., van den Heuvel-Panhuizen, M., de Lange, J., \& Wijers, M. (2007). Problem solving as a challenge for mathematics education in the Netherlands. ZDM Mathematics Education, 39(5-6), 405-418. https://doi.org/10.1007/s11858-007-0043-2

Dowker, A. (2003). Young children's estimates for addition: The zone of partial knowledge and understanding. In A.J. Baroody, \& A. Dowker (Eds.), The development of arithmetic concepts and skills: Constructing adaptive expertise (pp. 1-33). Mahwah, NJ: Lawrence Erlbaum Associates.

Frederiksen, N. (1984). Implications of cognitive theory for instruction in problem solving. Review of Educational Research, 54(3), 363-407. https://doi.org/10.3102/00346543054003363

Ganor-Stern, D. (2015). When you don't have to be exact: investigating computation estimation skills with a comparison task. Acta Psychologica, 154, 1-9. https://doi.org/10.1016/j.actpsy.2014.10.010

Geary, D.C. (2004). Mathematics and learning disabilities. Journal of Learning Disabilities, 37(1), 4-15. https://doi.org/10.1177/00222194040370010201

Gurbuz, R., \& Erdem, E. (2016). Relationship between mental computation and mathematical reasoning. Cogent Education, 3(1), 1-18. https://doi.org/10.1080/2331186X.2016.1212683

Hogan, T., \& Brezinski, K. (2003). Quantitative estimation: One, two, or three abilities? Mathematical Thinking and Learning, 5(4), 259-281. https://doi.org/10.1207/S15327833MTL0504_02

Holth, P. (2008). What is a problem? Theoretical conceptions and methodological approaches to the study of problem solving. European Journal of Behavior Analysis, 9(2), 157-172. https://doi.org/10.1080/15021149.2008.11434302

Jitendra, A.H., \& Star, J.R. (2012). An exploratory study contrasting high- and low- achieving students' percent word problem solving. Learning and Individual Differences, 22(1), 151-158. https://doi.org/10.1016/j.lindif.2011.11.003

Kasmer, L., \& Kim, O.K. (2011). Using prediction to promote mathematical understanding and reasoning. School Science and Mathematics, 111, 20-33. https://doi.org/10.1111/j.1949-8594.2010.00056.x

Kindrat, A.N., \& Osana, H.P. (2018). The relationship between mental computation and relational thinking in the seventh grade. Fields Mathematics Education Journal, 3, 6. https://doi.org/10.1186/s40928-0180011-4

LeFevre, J. A., Greenham, S. L., \& Naheed, N. (1993). The development of procedural and conceptual knowledge in computational estimation. Cognition and Instruction, 11(2), 95-132. https://oi.org/10.1207/s1532690xci1102_1

Lemaire, P., \& Lecacheur, M. (2002). Children's strategies in computational estimation. Journal of Experimental Child Psychology, 82(4), 281-304. https://doi.org/10.1016/S0022-0965(02)00107-8

Lemaire, P., \& Lecacheur, M. (2011). Age-related changes in children's executive functions and strategy selection: A study in computational estimation. Cognitive Development, 26(3), 282-294. https://doi.org/10.1016/j.cogdev.2011.01.002

Lester, F. K. Jr. (2013). Thoughts about research on mathematical problem-solving instruction. The Mathematics Enthusiast, 10(1). Retrieved from https://scholarworks.umt.edu/tme/vol10/iss1/12

Liljedahl, P., Santos-Trigo, M., Malaspina, U., \& Bruder, R. (2016). Problem solving in mathematics education. Springer Open. https://doi.org/10.1007/978-3-319-40730-2_1

McIntosh, A. J. (2005). Developing computation. Hobart: Department of Education, Tasmania.

Mcintosh, A. J., Reys, B. J., \& Reys, R. E. (1992). A proposed framework for examining number sense. For the Learning of Mathematics 12(3), 2-8. 
NCTM (2000). Principles and standards for school Mathematics. Reston, VA: NCTM.

Polya, G. (1973). How to solve it. Princeton, New Jersey: Princeton University Press.

Reys, R. E. (1984). Mental computation and estimation: Past, present and future. The Elementary School Journal, 84(5), 546-557. https://doi.org/10.1086/461383

Reys, R., Bestgen, B., Ryblot, J., \& Wyatt, J. (1982). Processes used by good computational estimators. Journal for Research in Mathematics Education, 13(3), 183-201. https://doi.org/10.2307/748555

Schoenfeld, A. (1992). Learning to think mathematically: Problem-solving, metacognition, and sense making in mathematics. In D.A. Grouws (Ed.), Handbook for research on mathematics teaching and learning (pp. 334-370). New York: MacMillan.

Segovia, I., \& Castro, E. (2009). Computational and measurement estimation: curriculum foundations and research carried out at the University of Granada. Electronic Journal of Research in Educational Psychology, 17(7), 1696-2095.

Sekeris, E., Verschaffel, L., \& Luwel, K. (2019). Measurement, development, and stimulation of computational estimation abilities in kindergarten and primary education: A systematic literature review. Educational Research Review, 27, 1-14. https://doi.org/10.1016/j.edurev.2019.01.002

Siegler, R. S., \& Booth, J. L. (2005). Development of numerical estimation: a review. In J.I.D., Campbell (Ed.), Handbook of mathematical cognition (pp. 197-212). New York: Psychology Press.

Silver, E. A., \& Cai, J. (1996). An analysis of arithmetic problem posing by middle school students. Journal for Research in Mathematics Education, 27(5), 521-539. https://oi.org/10.2307/749846

Sowder, J. T. (1992). Estimation and number sense. In D.A. Grouws (Ed.), Handbook of research on mathematics teaching and learning (pp. 371-389). New York, NY: Macmillan.

Stein, M. K., Boaler, J., \& Silver, E. A. (2003). Teaching mathematics through problem solving: Research perspectives. In H. L. Schoen, \& R. I. Charles (Eds.), Teaching mathematics through problem solving: Grades 6-12 (pp. 245-256). Reston, VA: NCTM.

Tsao, Y. L. (2009). Teaching computational estimation. In C.H. Yang (Ed.), Educational consulting book: Effective teaching methods (pp.45-54). Taiwan, Taipei: National Taipei University of Education.

Usiskin, Z. (1986). Reasons for estimating. In H. L. Schoen, \& M. J. Zweng (Eds.), Estimation and mental computation. NCTM. Reston, VA.

van de Walle, J. A., \& Lovin, L. H. (2006). Teaching student-centered mathematics: Grades K-3. New York: Pearson.

van den Heuvel-Panhuizen, M. (2001). Children learn mathematics. Utrecht, The Netherlands: Freudenthal Institute, Utrecht University.

Verschaffel, L., \& De Corte, E. (1997). Word problems: a vehicle for promoting authentic mathematical understanding and problem solving in the primary school. In T. Nunes, \& P. Bryant (Eds.), Learning and teaching mathematics: An international perspective (pp. 69-97). UK: Psychology Press Ltd.

Yang, D. C. (2019). Performance of fourth graders when judging the reasonableness of a computational result. International Journal of Science and Mathematics Education, 17(1), 197-215. https://doi.org/10.1007/s10763-017-9862-y 


\section{APPENDIX 1}

Computational Estimation Task (CET)

\begin{tabular}{|c|c|c|c|}
\hline \multicolumn{4}{|l|}{ Items } \\
\hline $\begin{array}{l}\text { A. } 476+338= \\
\text { a) approximately } 700 \\
\text { b) approximately } 800 \\
\text { c) approximately } 1000\end{array}$ & $\begin{array}{l}\text { B. } 0,8+0,02= \\
\text { a) approximately } 0,5 \\
\text { b) approximately } 0 \\
\text { c) approximately } 1\end{array}$ & $\begin{array}{l}\text { C. } 836-628= \\
\text { a) approximately } 100 \text { b) } \\
\text { approximately } 200 \\
\text { c) approximately } 300\end{array}$ & $\begin{array}{l}\text { D. } \frac{13}{16}-\frac{2}{6}= \\
\text { a) approximately } 0 \\
\text { b) approximately } \frac{1}{2} \\
\text { c) approximately } 1\end{array}$ \\
\hline $\begin{array}{l}\text { E. } 48 \times 76= \\
\text { a) approximately } 2.500 \\
\text { b) approximately } 3.000 \\
\text { c) approximately } 3.500\end{array}$ & $\begin{array}{l}\text { F. } \frac{9}{11} \times \frac{2}{9}= \\
\text { a) approximately } 0 \\
\text { b) approximately } \frac{1}{2} \\
\text { c) approximately } 1\end{array}$ & $\begin{array}{l}\text { G. } 848: 74= \\
\text { a) approximately } 10 \\
\text { b) approximately } 20 \\
\text { c) approximately } 100\end{array}$ & $\begin{array}{l}\text { H. } 19,08: 0,6= \\
\text { a) approximately } 10 \\
\text { b) approximately } 20 \\
\text { c) approximately } 30\end{array}$ \\
\hline
\end{tabular}




\section{APPENDIX 2}

\section{Problem Solving Task (PST)}

\section{Items}

A. There are 5 schools with 8 classes in each school. Each class has 20 students. If these students were equally distributed in 10 schools, how many students would each school have?

a) 120 b) 100 c) 150

B. A dolphin has jumped 8 meters out of a 3-meter deep pool. How many meters has the dolphin gone from the water level?

a) $12 \mathrm{~m} \mathrm{b)} 5 \mathrm{~m} \mathrm{c)} 11 \mathrm{~m}$

C. Young people generally drive fast. Although the old people drive slowly, they have an attention deficit problem. It is observed that out of 50 car accidents that happened in the past month, the drivers of 25 accidents were young. Do you think the driver in a possible $51^{\text {st }}$ accident will be young or old?

a) The driver will probably be young.

b) The driver will probably be old.

c) The possibility of the driver to be old and young is equal.

D. The area filled with water on earth is more than the area that is filled with land. From time to time, some meteors fall to any place on earth. Do you think the possibility of these meteors falling on land is higher than falling on water?

a) The possibility of falling on land is higher.

b) The possibility of falling on water is higher.

c) The possibility of falling on land and water is equal.

E. A farmer has two square-shaped gardens and wants to plant tomatoes in the larger garden. For one garden he knows that its area is 36 square meters and for the other garden he knows that its perimeter is 28 meters. In which garden is it more worthy to sow tomatoes?

a) It is more worthy to sow tomatoes in the garden that has an area of 36 sq.m.

b) It is more worthy to sow tomatoes in the garden that has a perimeter of $28 \mathrm{~m}$.

c) It is equally worthy to sow tomatoes in either garden.

F. Two people are looking in the same direction. One makes a 180 degree turn and the other a 360 degree turn. Where is each one looking now?

a) They are both looking in the initial direction.

b) One of them is looking in the initial direction and the other in the opposite direction.

c) Both of them are looking different directions from the initial.

G. Which number is missing in the following number pattern?

$\frac{1}{16} \frac{1}{8} \frac{1}{4} ? 12$

a) $\frac{1}{3}$ b) $\frac{1}{5}$ c) $\frac{1}{2}$

H. Which shape comes after the following pattern of shapes?

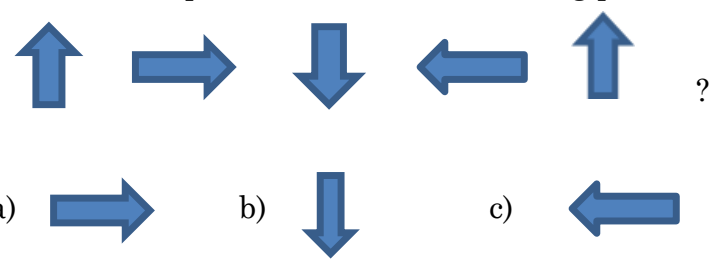

